\title{
Examining the Development of Professional Dispositions of Prospective Teachers in Higher Education: Broadening the Horizon of Teacher Training
}

\author{
Muhammad Riaz', Muhammad Uzair ul Hassan ${ }^{2}$
}

\begin{abstract}
In 2009, dispositions were included in the professional standards by the National Accreditation Council for Teacher Education (NACTE) in Pakistan. As per NACTE's manual, teacher training institutes are responsible to develop and assess prospective teachers' dispositions. However, no research study in Pakistan illustrates whether teacher training institutions are assessing pre-service teachers' professional dispositions. Therefore, the basic purpose of the study was to examine and measure the professional dispositions of pre-service teachers of teacher education programs in Pakistan. The quantitative cross-sectional research design was opted to accomplish the research study. The researchers visited 11 out of 15 public universities of Punjab. Hence, data were collected from 1061 out of 1592 prospective teachers through proportionate stratified sampling. For data collection, a self-assessment questionnaire was used which was developed by reviewing extensive literature consistent with dispositions mentioned in National Professional Standards for Teachers in Pakistan (NPSTP). The study concluded that albeit pre-service teachers did not possess equally all, and hence, partly possessed professional dispositions, mentioned in National Professional Standards for Teachers. Prospective teachers from South Punjab reflected significantly more professional dispositions as compared to prospective teachers of Central and North Punjab. The NACTE may guide and provide information to teacher training institutions for developing, monitoring and assessing the prospective teachers' professional dispositions to launch a better workforce for educational institutions.
\end{abstract}

Keywords: Professional Dispositions, Prospective Teachers, Teacher Training Institutes, Professional Standards

\section{Introduction}

Professional dispositions are considered an integral part of teachers and teacher education programs throughout the world. These are equally important

\footnotetext{
${ }^{1} \mathrm{PhD}$ Scholar, Department of Education, University of Sargodha, Sargodha Email: mianriaz90@gmail.com

${ }^{2}$ Associate Professor, Department of Education, University of Sargodha, Sargodha ,Email: uhassan74@gmail.com
} 
for effective teaching as content knowledge and teaching skills. Teachers, having professional dispositions, know when and how to respond students' needs by recognizing the best suitable practice according to the situation which can help students to learn effectively (Darling-Hammond \& Bransford, 2007). According to Wasicsko (2007), dispositions are evident through literature as an important and critical component for the effectiveness of teachers and teachers' quality.

Professional disposition is a blended term which includes beliefs, values and behaviors towards the profession of teaching. For example, if a teacher believes that all students should be treated equally regardless of their needs/talents, on the other hand, if a teacher believes that all students should be treated according to their needs/talents both the teachers will act differently and both the teachers will adopt different teaching strategies. Villegas (2007) described that people tend to act in different ways during a specific situation due to their beliefs. Equally, the teaching profession demands to follow some moral and ethical values. For example, if a teacher does not have respect for others, does not show tolerance on occasions where needed, uses abusive language in the classroom and calls bad names of the students, these immoral and unethical values will impact negative effects on students and their learning. Similarly, the behaviors of the teachers also matter a lot in the teaching profession. For example, if a teacher interacts with colleagues, students, parents and community members in a polite, humble, caring and respectful manner this will definitely leave pleasant effects on others. According to Murray (2007), dispositions are those characteristics of pre-service teachers' behaviors that are displayed through actions in the classroom. Ruitenberg (2011) suggested that teaching programs should focus on future teachers' dispositional development in a manner that they can respond and behave according to the situations while teaching. Wasicsko (2007) argued that pre-service teachers' fundamental and core perceptions such as beliefs, opinions, attitudes and values do not change abruptly but change gradually. Teaching programs could help to change pre-service teachers' beliefs, perceptions and values regarding teaching through a variety of courses.

Prospective teachers equip themselves with necessary content knowledge and skills which are important to be an effective teacher during the training. Therefore, dispositions were included as an essential part of teacher education programs in the form of observable behaviors and ways of their acting (Meidl \& Baumann, 2015). In this regard, many countries of the world have developed and adopted standards for their teacher training institutes. Wise and Liebbrand (2000) stated that teacher training institutes must prepare teachers according to the given state/national standards. Pakistan also has developed some national standards for teachers. These standards include knowledge, skills and dispositions for effective 
teaching-learning to take place in the classrooms. In Pakistan, National Accreditation Council for Teacher Education (NACTE) also requires the measurement of dispositions as part of its accreditation requirements for teaching programs of teacher training institutes. According to NACTE's documents training institutes for teachers are liable for the development and assessment of prospective teachers' dispositions. However, none of the documents is available to show that these institutes are assessing professional dispositions of prospective teachers. These circumstances demand the current research study; therefore the basic purpose of the study was to examine and measure the professional dispositions of pre-service teachers of teacher education programs in Pakistan.

\subsection{Objectives of the Study}

The objectives of the present research study were:

1. Assessing the prospective teachers' professional dispositions.

2. Identifying the differences among prospective teachers' dispositions on the basis of various demographics.

3. Exploring relationship between professional dispositions and academic achievements of prospective teachers.

\subsection{Research Questions}

Following were the research questions of the study:

1. Do pre-service teachers 'possess professional dispositions?

2. Do professional dispositions of prospective teachers differ on the basis of region, gender and teaching programs?

3. Do professional dispositions of pre-service teachers differ on the basis of universities within the region?

4. Do pre-service teachers' professional dispositions correlate with their academic achievements?

\section{Literature Review}

According to Hillman, Rothermel and Scarano (2006), professional dispositions help teachers in shaping and creating a teaching-learning situation in which schoolchildren are engaged effectively to enhance their learning. Therefore, it is necessary to assess the professional dispositions of studentteachers during their respective teaching programs. According to Duplass and Cruz (2010), professors must assess, record and report the professional dispositions of prospective teachers whether they possess appropriate professional dispositions to join the teaching profession. They also described that assessing prospective teachers' knowledge and skills by teacher educators in a traditional way is not sufficient. Teacher educators must assess prospective teachers during the whole academic program whether they are fit for the teaching profession or not. 
Jensen (2004) stated that in the field of education, there is a lot of information regarding how to assess the content knowledge (what teachers know) and teaching skills (what teachers can do) but how to assess the professional dispositions of teachers is still developing and under process. She highlighted even a more puzzling situation that why numerous teacher-educators succeed with certain students but why not with all the students. She also stated that when students, parents and other people are asked about their best as well as worst teachers, most of the time they describe teachers' dispositional characteristics. Similarly, when pre-service teachers are asked about their teacher educators they also describe dispositions rather than describing their good content knowledge and teaching skills.

Bolshakova, Johnson and Czerniak (2011) stated that teachers are those persons who could inspire the students to get higher achievement and success having caring, supportive, kind, respectful and sympathetic relations with students. McGinley and Jones (2014) concluded that caring attitude of teachers at the very beginning of their career helps to increase the engagement of students in the classroom. This could be practiced by teachers having a smile, talking with students according to their areas of interest and engaging them in activities within the classroom. On the contrary, teachers who do not have appropriate dispositions could negatively affect students' learning. According to Crumpton and Gregory (2011), if students are not motivated regularly and frequently by rewards, prizes and incentives then they do not see schooling to achieve future aims. According to Gillet, Vallerand and Lafreniere (2012), research has supported the notion that for increasing the efficiency and academic achievements of students it is very essential to have teachers equipped with professional dispositions in the classrooms who remain connected effectively with students.

Neugebauer (2011) conducted a research study to find out the most important and essential qualification of pre-service educators including their training, dispositions and degrees. The results of the study were that the development and improvement of dispositions (caring and loving dispositions towards children) are essential characteristics of pre-service educators. There is no doubt that trainee teachers must be trained in teaching skills and content knowledge to deliver in a better mode within the classroom but the outcomes of Neugebauer's study are emphasizing the significance of developing dispositions for the creation of a conducive learning environment.

Payne and Summers (2008) described that teacher training institutes should explore pre-service teachers' dispositions as safety measures for students and schools not only having the content knowledge but they must have positive 
dispositions for creating a good learning atmosphere for the students. They have recommended that assessment of student-teachers' dispositions are very essential to produce effective future teachers. Teachers who have professional dispositions could use their abilities in selecting and adapting teaching strategies consistent with the requirements of the students over and above professional dispositions are found helpful for teachers in dealing with challenging situations within the classroom (Parrott, Ros-Voseles, Denise, \& Eaton, 2013) as well as for the engagement of students in effective teaching-learning process.

According to Taylor and Wasicsko (2000), prospective teachers must know that professional dispositions are very important and significant like teaching skills and content knowledge to be an effective tutor. Therefore, teachers should consider themselves professional teachers and they should cultivate this thinking during their stay at teacher training institute rather than they wait to join the teaching profession. Dispositions had long-lasting effects on the career and future teaching of prospective teachers so they should be attentive that their dispositions will be checked and monitored consistently during course work and teaching practice for their sound professional development (Rike \& Sharp, 2008).

Teacher training institutes and teaching programs must benefit prospective teachers in understanding how dispositions affect lesson planning, teaching styles, job satisfaction and help to fit in the teaching profession. Moreover, an awareness regarding professional dispositions among pre-service and what is being expected of them may provide teacher candidates opportunities to think deeply about the requirements, expectations and demands of the teaching profession (Priyadharshini \& Robinson-Pant, 2003). Therefore, dispositional development awareness among pre-service teachers would help them to apply learned theories and skills during teaching programs for actual classroom settings while teaching students (Wilkerson \& Lang, 2007).

Teacher candidates' self-awareness about dispositions and development process helps to develop and improve the desired dispositions. According to Schussler, Stooksberry and Bercaw (2010), self-assessment is a process through which prospective teachers are made aware of the dispositions which are expected to manifest in certain situations. They further discussed that teacher candidates' reflection regarding their own moral and ethical values, traditions and culture could help them in deciding about the instructional and pedagogical methods according to the culture and diversity of the students. Rinaldo et al. (2009) concluded that the dispositions of prospective teachers might be improved and developed through self-reflection. Dottin (2009) argued that if teacher educators are well aware of their own professional dispositions then they will be 
able to create a purposeful teaching-learning environment for the achievement of the objectives.

Why should dispositions be assessed? Carroll (2011) replied to the question in this way that pre-service teachers' dispositions must be assessed so that unqualified or teachers who are not capable of teaching could not get access to the classroom or by determining unqualified teachers, teacher educators could help them in developing the required dispositions. Helm (2006a) described that through dispositional assessment, it is identified which and to what extent professional dispositions are present in prospective teachers. Carroll (2005) described that assessment of required dispositions is a way to make the invisible observable through different structured and unstructured ways. He focused on the assessment of dispositions by using the criteria which must be public, clear, open, explicit and morally as well as ethically based.

\section{Research Methodology}

Following is being given the methodology of the current study:

\subsection{Research Design}

The quantitative cross-sectional research design was opted to accomplish the research study.

\subsection{Population of Study}

The population of the current study was consisted of prospective teachers studying and getting training at teacher training institutes of public universities of Punjab. Geographically Punjab has three regions namely Northern, Central and Southern Punjab.

\subsection{Sample and Sampling Technique}

The number of universities varies in each region therefore; a proportionate stratified sampling was used to make the sample representative of the population. Fluid Surveys Team (2014) calculated sample size 310 for the accessible population of 1592 (student-teachers of final semester belonging to M.A Education and BS Education/B. Ed Honors) with 95\% confidence level and $5 \%$ margin of error. Further, sample size for North, South and Central Punjab was calculated 22, 82 and 207 respectively with respect to proportion of studentteachers existing in the accessible population. But researchers tried to collect maximum data and hence, data were collected from 1061 prospective teachers (341 out of 419, 667 out of 1060 and 53 out of 113 from South, Central and North Punjab respectively) of public universities of Punjab.

\subsection{Instrumentation}

In order to collect data self-assessment five point Likert-type scale was developed having 98 items with the help of extensive literature in accordance with dispositions mentioned in NPSTP. There were nine indicators i.e. belief that 
all students can learn, passion for teaching, diversity, collaboration, critical thinking, fair assessment, moral values, commitment to effective communication and commitment to students' learning having 10,10, 16, 18, 7, 6, 9, 11 and 11 items respectively. Validity was ensured through experts' opinions. For ensuring reliability, a pilot study was conducted to 53 student-teachers of three public universities of Punjab. Analyzed data indicated appropriate internal reliability in terms of Cronbach's alpha calculating the value .91 .

\subsection{Data Collection}

Final data for the present research study were collected in May and June 2019. The researchers visited universities of all the three regions of Punjab personally and collected the required data. Before applying different parametric tests, normality of data and homogeneity of variances were checked and these were found acceptable and satisfactory.

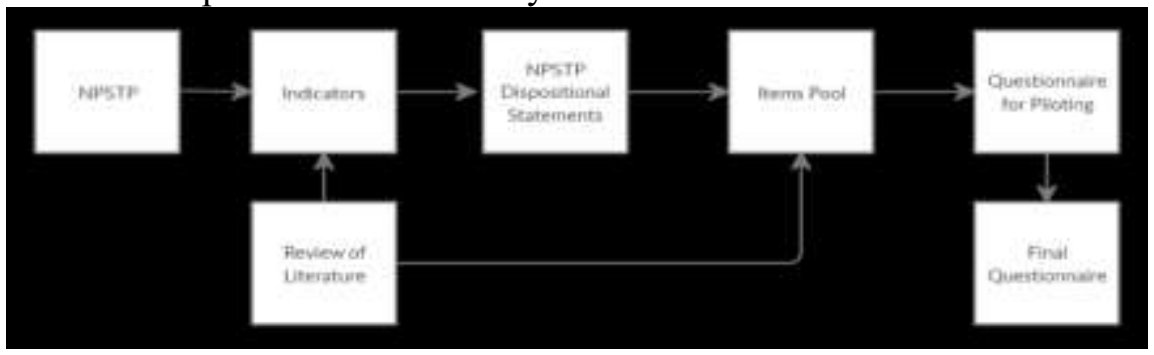

Figure 1: Researchers' concept for identification and assessment of dispositions

\section{Data Analysis and Interpretation}

The analysis of pre-service teachers' demographics exposed that $32.1 \%$, $62.9 \%$ and $5.0 \%$ pre-service teachers were from South, Central and North Punjab respectively. Teaching program wise distribution showed that $56.6 \%$ pre-service teachers were from M. A. Education and $43.4 \%$ were from BS/B. Ed. Honors. Gender wise distribution showed that $17.3 \%$ pre-service teachers were male and $82.7 \%$ were female. The mean score of female pre-service teachers was a little bit more than male pre-service teachers. But independent samples $t$-test revealed no significant difference between professional dispositions of male and female pre-service teachers. Whereas, indicator wise analysis revealed that female preservice teachers had significantly more professional dispositions regarding moral/ethical values than male pre-service teachers.

Table 4.1

Comparing overall professional dispositions on the basis of regions of Punjab

\begin{tabular}{lllcc}
\hline Dispositions & Variance & $d f$ & $F$ & Sig. \\
\hline Self-Assessed & Between Groups & 2 & 4.880 & .008 \\
& Within Groups & 1058 & & \\
& Total & 1060 & & \\
\hline
\end{tabular}


Table 1 displayed significant differences in the self-assessed dispositions on the basis of regions of Punjab $F(2,1058)=4.880, p<.05$. Following table shows the LSD post hoc test results for above mentioned comparison:

Table 4.2

LSD post hoc comparison of regions of Punjab

\begin{tabular}{cccccc}
\hline $\begin{array}{c}\text { Dependent } \\
\text { Variable }\end{array}$ & $\begin{array}{c}\text { (I) Regions } \\
\text { of Punjab }\end{array}$ & $\begin{array}{c}\text { (J) Regions } \\
\text { of Punjab }\end{array}$ & $\begin{array}{c}\text { Mean } \\
\text { Difference (I-J) }\end{array}$ & $\begin{array}{c}\text { Std. } \\
\text { Error }\end{array}$ & Sig. \\
\hline $\begin{array}{c}\text { Self-Assessed } \\
\text { Dispositions }\end{array}$ & $\begin{array}{c}\text { South } \\
\text { Punjab }\end{array}$ & $\begin{array}{c}\text { Central } \\
\text { Punjab }\end{array}$ & 9.111 & 2.9214 & .002 \\
\hline
\end{tabular}

Table 4.2 showed the LSD post hoc comparison of prospective teachers' self-assessed dispositions. According to comparison pre-service teachers from South Punjab had significantly more professional dispositions than prospective teachers from Central Punjab.

Table 4.3

Comparing professional dispositions on the basis of teaching programs

\begin{tabular}{llllllll}
\hline Dispositions & $\begin{array}{l}\text { Program of } \\
\text { study }\end{array}$ & $N$ & Mean & $S D$ & $t$ & $d f$ & Sig. \\
\hline Self- & M.A. & 600 & 406.112 & 43.561 & 3.468 & 1059 & .001 \\
Assessed & $\begin{array}{l}\text { Education } \\
\text { BS/B. Ed. }\end{array}$ & 461 & 396.701 & 44.147 & & & \\
& $\begin{array}{l}\text { Hons } \\
\text { Hons }\end{array}$ & & & & & & \\
\hline
\end{tabular}

Table 4.3 displayed a significant difference in the professional dispositions of pre-service teachers from M.A. Education $(M=406.112, S D=43.561)$ and preservice teachers from BS/B.Ed. Honors $(M=396.701, S D=44.147), t=3.468, p=$ $<.05$. Pre-service teachers of M.A. Education depicted more professional dispositions as compared to student-teachers of BS/B.Ed. Honors in Education.

Table 4.4

Comparing overall professional dispositions on the basis of universities of South Punjab

\begin{tabular}{clccc}
\hline Dispositions & \multicolumn{1}{c}{ Variance } & $d f$ & $F$ & Sig. \\
\hline Self-Assessed & Between Groups & 6 & 2.399 & .028 \\
& Within Groups & 334 & & \\
& Total & 340 & & \\
\hline
\end{tabular}

Table 4.4 displayed a significant difference in the professional dispositions on the basis of universities of South Punjab $F(6,334)=2.399, p<$ .05 ; student-teachers from Ghazi University depicted more professional dispositions as compared to pre-service teachers from other universities of the region. 
Table 4.5

Comparing professional dispositions on the basis of universities of Central Punjab

\begin{tabular}{clccc}
\hline Dispositions & \multicolumn{1}{c}{ Variance } & $d f$ & $F$ & Sig. \\
\hline Self-Assessed & Between Groups & 8 & 3.736 & .000 \\
& Within Groups & 658 & & \\
& Total & 666 & & \\
\hline
\end{tabular}

Table 4.5 displayed a significant difference in the professional dispositions on the basis of universities of Central Punjab $F(8,658)=3.736, p<$ .05 ; student-teachers from University of Sargodha and University of Education, Jauharabad Campus depicted more professional dispositions than pre-service teachers from other universities of the region.

Table 4.6

Pearson Correlation between pre-service teachers' professional dispositions and CGPA

\begin{tabular}{lcc}
\hline Variable & Self-assessed Dispositions & CGPA \\
\hline Self-assessed Dispositions & 1 & \\
CGPA & .041 & 1 \\
\hline Ne1061 & &
\end{tabular}

$\mathrm{N}=1061$

Table 4.6 displayed that future teachers' professional dispositions and their academic achievements (CGPA) are not significantly correlated $\mathrm{r}=$ $.041, p=<.05$.

\section{Discussion}

In general, significant differences were observed among future teachers' professional dispositions on the basis of regions of Punjab. These differences might be due to the cultural norms and traditions which vary from region to region. Brindle (2012) also reported significant differences among student teachers' dispositions of Western, Central and Eastern areas of the state when they were compared on geographical basis but Brindle did not describe the reason for the differences.

On the basis of gender, no significant differences were observed in the results of prospective teachers' professional dispositions. It may be due to the fact that male and female prospective teachers are being taught the same curriculum in the same environment under one roof. However, a difference was calculated in the male and female self-assessed dispositions on the category "moral/ethical values". The difference may be due to the reason that females are considered more polite, courteous and tend to follow cultural taboos and values. In Pakistani culture, females are more emphasized while giving them training and 
advice at homes to follow the family rules, norms and values. Many other researchers also reported no significant differences in the male and female prospective teachers' dispositions (Schulte, Edick, Edwards \& Mackiel, 2005) however; Kirchner (2011) concluded that female student teachers had more dispositions than male student teachers. Kirchner also illustrated that on 36 out of 45 professional dispositions, female student teachers significantly exhibited more dispositions than male student teachers.

Aggregate results on the basis of teaching programs revealed that prospective teachers from M.A Education depicted more self-assessed dispositions than pre-service teachers from BS/B.Ed. Honors. The possible reasons include; (a) candidates seeking admission in M. A. Education are more mature at the time of admissions in the universities (b) it may be prospective teachers from M.A. Education have more aptitude towards the teaching profession than prospective teachers from BS/B.Ed. Honors (c) many students of BS/B.Ed. Honors join education department by chance as they could not get admissions in their preferred disciplines and due to the semester system in universities, candidates want to join any department in which admissions could be possible instead of getting education through annual system. Brindle (2012) also found difference among prospective teachers on the basis of teaching programs and concluded with respect to students' enrollment that in larger teaching programs (more than 250 students), student teachers' dispositions were assessed less as compared to student teachers who were enrolled in small-sized teaching programs (up to 50 students). Whereas in the present study, prospective teachers from small-sized institutions depicted more self-assessed and taught professional dispositions. It is possible that in small-sized teaching programs teacher educators pay more attention towards prospective teachers' learning process.

Significant differences were observed among prospective teachers' professional dispositions of all public universities of Punjab. Prospective teachers of universities situated in the same city of Punjab also depicted different selfassessed dispositions. The difference is due to the reasons that every university has a unique culture (more or less conservative), teaching environment, rules, regulations, teachers having a variety of experiences and personalities etc. In fact, it is not a matter of teaching dispositions only through content or courses but teacher educators' behaviors, interactions with prospective teachers within and outside the classroom, teacher educators' workload, teaching experience and dedication to produce quality teachers, environment and culture of teacher training institutes, teaching practice, school environment for teaching practice and guidance from school teachers in addition to teacher educators during 
teaching practice, all these affect pre-service teachers' dispositions. There may be many reasons for the differences among prospective teachers' dispositions but it also demands additional research to find out the full picture based on empirical data.

No correlation was observed between academic achievements (CGPA) and professional dispositions of prospective teachers. It means student-teachers having average marks may have better and appropriate dispositions to teach whereas student-teachers' higher academic achievements do not guarantee their good and appropriate professional dispositions. But the government always recruited teachers only on the basis of higher marks even sometimes government prefer non-trained teachers having master degree in any discipline. The nontrained teachers (if recruited) cause to damage the personality of students in a number of ways almost for a period of 25-30 years. Untrained teachers do not know how to deal with students having different abilities even; they do not know teaching methods and how to choose suitable teaching strategy (ies) according to the situation of the classroom. Therefore, the government should consider the prospective teachers of different teaching programs who have content knowledge, teaching skills and professional dispositions while recruiting process to teach students effectively in the educational institutions of the country.

\section{Conclusions}

The study concluded although prospective teachers possessed few of the professional dispositions mentioned in NPSTP. Overall results indicate an optimistic image that professional dispositions are being developed among prospective teachers in their respective teaching programs but there is less emphasis on all dispositions by the faculty of teacher training institutes of universities. Though, NACTE has made responsible teacher training institutes to develop and assess prospective teachers' professional dispositions but none kind of mechanism has been defined nor approved to develop and assess dispositions. The partially possessed dispositions are being developed as a result of teaching programs that are being run in a traditional way to impart knowledge and teaching skills. So as to dispositions related to collaboration are being developed among prospective teachers as a result of forming various groups of the varied ratio of male and female students to accomplish assignments. Courses educational psychology and teaching methods also help in developing professional dispositions.

There is more need at every region to address the professional dispositions of prospective teachers to meet the equal level in all the regions of Punjab. It is also confirmed on the basis of other demographic variables like teaching programs that differences are existed among pre-service teachers' 
professional dispositions. So it is concluded that professional dispositions of prospective teachers should be focused on every teaching program equally to equip prospective teachers with appropriate dispositions to teach students effectively in the future. This study may be a guide to establish procedures for assessing the prospective teachers' dispositions.

It is also concluded that no correlation was observed between prospective teachers' self-assessed dispositions and academic achievements (CGPA) and vice-versa. Government policies for the recruitments of teachers in Pakistan are bizarre. Prospective teachers having professional dispositions and training are not hired to teach even at the primary level. The government often recruits candidates who have no teachers' training certificate or degree because it has been concluded that teaching programs and courses help prospective teachers to develop professional dispositions among themselves. On the contrary, teachers having no training, insufficient and inappropriate professional dispositions could cause the damage of their students in a way that is irreversible.

\section{Recommendations}

1. The training institutes for teachers should start to assess prospective teachers' dispositions as soon as possible in order to develop all the required dispositions among prospective teachers mentioned in the document of NPSTP.

2. The HEC and NACTE may introduce some courses based on professional dispositions in order to develop all the professional dispositions among prospective teachers equally mentioned in NPSTP so that a better workforce may be available to teach effectively in educational institutions of Pakistan.

3. The teacher training institutes of universities should collaborate to minimize the existing variations among prospective teachers' dispositions because a list of required dispositions has been provided in NPSTP for teacher training institutes to be followed. Sharing information with respect to professional dispositions will help teacher training institutions to develop the required dispositions equally among preservice teachers at appropriate level.

4. The government should not recruit teachers only on the basis of candidates' academic achievements (marks) but government should consider their professional dispositions at the time of recruitment process because teachers having appropriate professional dispositions could have prodigious positive effects on the overall development of students. 


\section{References}

Bolshakova, V. L., Johnson, C. C., \& Czerniak, C. M. (2011). "It depends on what science teacher you got": urban science self-efficacy from teacher and student voices. Cultural Studies of Science Education, 6(4), 961.

Brindle, S. E. (2012). An exploratory study on the assessment of pre-service teacher dispositions by teacher education programs in Iowa (Doctoral dissertation, Drake University).

Carroll, D. (2005). Developing dispositions for teaching: Teacher education programs as moral communities of practice. The New Educator, 1(2), 81100 .

Carroll, D. (2011). Developing dispositions for ambitious teaching. Journal of Educational Controversy, 6(1), 1-8.

Corbett, D., \& Wilson, B. (2002). What urban students say about good teaching. Educational Leadership, 60(1), 18-23.

Crumpton, H. E., \& Gregory, A. (2011). "I'm not learning": The role of academic relevancy for low-achieving students. The Journal of Educational Research, 104(1), 42-53.

Darling-Hammond, L., \& Bransford, J. (Eds.). (2007). Preparing teachers for a changing world: What teachers should learn and be able to do. John Wiley \& Sons.

Dottin, E. S. (2009). Professional judgment and dispositions in teacher education. Teaching and teacher education, 25(1), 83-88.

Duplass, J. A., \& Cruz, B. C. (2010). Professional dispositions: What's a social studies education professor to do?. The Social Studies, 101(4), 140-151.

FluidSurveys Team (2014, July 8). Calculating the right survey sample size. Retrieved from http://fluidsurveys.com/university/calculating-rightsurvey-sample-size/

Gillet, N., Vallerand, R. J., \& Lafrenière, M. A. K. (2012). Intrinsic and extrinsic school motivation as a function of age: The mediating role of autonomy support. Social Psychology of Education, 15(1), 77-95. 
Government of Pakistan. (2009). National professional standards for teachers in Pakistan.

Helm, C. M. (2006a). Teacher dispositions as predictors of good teaching. The Clearing House: A Journal of Educational Strategies, Issues and Ideas, 79(3), 117-118.

Hillman, S. J., Rothermel, D., \& Scarano, G. H. (2006). The assessment of preservice teachers' dispositions. The Teacher Educator, 41(4), 234-250.

Jensen, D. L. R. (2004). Teacher candidate dispositions identified by NCATEaccredited colleges of education: How professional educators are disposed toward the students, curriculum, and reasons they teach. (Doctoral Dissertation, University of North Dakota).

Kirchner, S. (2011). First-year teachers' dispositions: exhibited and perception of being taught. (Doctoral Dissertation, Kansas State University).

McGinley, J. J., \& Jones, B. D. (2014). A brief instructional intervention to increase students' motivation on the first day of class. Teaching of Psychology, 41(2), 158-162.

Meidl, T., \& Baumann, B. (2015). Extreme make over: Disposition development of pre-service teachers. Journal of Community Engagement and Scholarship, 8(1), 90.

Murray, F. B. (2007). Disposition: A superfluous construct in teacher education. Journal of teacher education, 58(5), 381-387.

Neugebauer, R. (2011). TRENDS: Qualifications of Preschool Teachers-A Hot Issue in Our Field. Exchange-Early Childhood Leaders, 33(6), 23.

Parrott, M. Y., Ros-Voseles, D., Denise, A., \& Eaton, P. (2013). A Picturesque View of Dispositions, Autonomy, and Efficacy during the Educational Preparation of Early Childhood Educators. Online Submission.

Payne, M., \& Summers, D. G. (2008). From thought police to thoughtful practice: The evolution of dispositions assessment in a teacher education program. Teaching and learning, 23(1), 40-47. 
Priyadharshini, E., \& Robinson-Pant, A. (2003). The attractions of teaching: An investigation into why people change careers to teach. Journal of Education for Teaching, 29(2), 95-112.

Rike, C. J., \& Sharp, L. K. (2009). Developing and assessing teacher candidates' dispositions: A beneficial process for all. Affective teacher education: Exploring connections among knowledge, skills, and dispositions, 61-77.

Rinaldo, V. J., Denig, S. J., Sheeran, T. J., Cramer-Benjamin, R., Vermette, P. J., Foote, C. J., \& Smith, R. M. (2009). Developing the Intangible Qualities of Good Teaching: A Self-Study. Education, 130(1), 42-52.

Rockoff, J. E. (2004). The impact of individual teachers on student achievement: Evidence from panel data. American economic review, 94(2), 247-252.

Ruitenberg, C. W. (2011). The trouble with dispositions: A critical examination of personal beliefs, professional commitments and actual conduct in teacher education. Ethics and Education, 6(1), 41-52.

Schulte, L., Edick, N., Edwards, S., \& Mackiel, D. (2005). The development and validation of the Teacher Dispositions Index. Essays in Education, 12(1), 7.

Schussler, D. L., Stooksberry, L. M. \& Bercaw, L. A. (2010). Understanding teacher candidate dispositions: Reflecting to build self-awareness. Journal of Teacher Education, 61(4), 350-363.

Taylor, R. L., \& Wasicsko, M. M. (2000, November). The dispositions to teach. In annual meeting of the Southern Region Association of Teacher Educators (SRATE) Conference, Lexington, KY.

Villegas, A. M. (2007). Dispositions in teacher education: A look at social justice. Journal of Teacher Education, 58(5), 370-380.

Wasicsko, M. M. (2007). Dispositions-A perceptual approach. ME Diez \&]. Raths (Eds.), Dispositions in teacher education, 53-89.

Wilkerson, J. R., \& Lang, W. S. (2007). Assessing teacher dispositions: Five standards-based steps to valid measurement using the DAATS model. Thousand Oaks: Corwin Press. 
Wise, A. E., \& Leibbrand, J. A. (2000). Standards and teacher quality. Phi Delta Kappan, 81(8), 612.

\section{Citation of this Article:}

Riaz, M., \& Hassan, U (2020). Examining the Development of Professional Dispositions of Prospective Teachers in Higher Education: Broadening the Horizon of Teacher Training. International Journal of Innovation in Teaching and Learning (IJITL), 6(2), 170-185. 